\title{
Preserving Language Diversity for Sustainable Development in Nigeria
}

\author{
Eucharia Okwudilichukwu Ugwu, \\ University Of Ibadan, Ibadan, Nigeria
}

Doi:10.19044/esj.2020.v16n11p83 ～URL:http://dx.doi.org/10.19044/esj.2020.v16n11p83

\begin{abstract}
In Nigeria, the local people speaking the many indigenous languages represent ethnolinguistic minorities that are often the most disadvantaged. Speakers of indigenous languages seem to lack access to information, quality education, social services, and meaningful government presence. In order to achieve the sustainable development goals set by the UN in Nigeria, its rich linguistic diversity must be recognised so that the local people can stay informed, actively participate in, and fully enjoy the initiatives of the government aimed at improving the quality of life of the citizens. Quality education, besides holding the key to information and empowerment, also opens the door to creativity, innovation and preparation of skilled people in the present science- and technology-driven world. Modern forms of agriculture, health information, sanitation and best practices in almost all aspects of life are easily accessible to the literate members of the society. In Nigeria, English is an obstacle to successful learning both in formal and informal education. In the light of the above, this paper emphasises the role and importance of the indigenous languages in sustainable development. It also makes a strong case for the use of mother tongue-based multilingual education in Nigeria.
\end{abstract}

Keywords: Language diversity, sustainable development in Nigeria, mother tongue-based education, ethnolinguistic minorities

\section{Introduction}

The Sustainable Development Goals (SDGs), also known as the 2030 Agenda represent 17 broad goals set by the United Nations, in 2015, at the expiration of the Millennium Development Goals (MDGs). Poverty reduction, ending of armed conflicts as well as different forms of hazards are fundamental to the goals. Language is a tool for both inclusion and exclusion. Although English, as a world language, plays many essential roles in Nigeria, it has equally tended to exclude many local people from the developmental 
agenda. Sustainable development is about "recreating a safe world for all, through equipping of every human being with the tools for a decent and healthy living" (Ugwu \& Ogunremi, 2019, p. 53). Thus, achieving the 17 SDGs requires making people responsible for their own growth and survival by opening up opportunities that would enable them to live life fully. In Nigeria, this requires respecting the fundamental human rights and the creation of a conducive environment where human potentials can be developed and existential problems can be faced. The wide gap between the rich and the poor needs to be narrowed and eventually closed.

"Language is power: it means economic opportunity for those whose language is privileged by the state" (de Varennes, 2010, p. 268). Unfortunately, many indigenous languages are not given due recognition by the Nigerian government and are barely surviving. This means that millions of Nigerians who cannot speak English but rely on the indigenous languages are disempowered and not able to participate fully in the national life. Information and knowledge are essential elements for sustainable development, and they should be delivered to the nooks and crannies of the society in a language that they understand. Language is needed to disseminate information, breaking the chains of ignorance, illiteracy, and intellectual poverty. In a multilingual nation such as Nigeria, the indigenous languages are vital, while linguistic assimilation forcing all Nigerians to speak English on the pretext of development has been the norm. Actually, sustainable development needs meeting people in their different situations, entering their worlds in order to understand their experiences and aspirations, and building into what they already have. Indigenous languages harbour the experiences of their speakers and they are the best channels through which any plan geared towards achieving the SDGs must be conveyed. Unfortunately, the "prevailing policies have generally entailed assimilation and integration into the dominant society's modes of production and employment, often requiring migration or forced relocation to urban areas" (Romaine, 2015, p. 36). Furthermore, many indigenous peoples who associate their disadvantaged social position with their languages and culture tend to see these as hindrances towards a better life; consequently, they abandon their languages and cultures, hoping that this would enable them to overcome discrimination, improve their lives, enhance social mobility, and assimilate into the global marketplace (UNESCO, 2003a, p. 2).

No language is without potentials for development as long as people use it to function in their daily life. Developing the orthographies of as many local languages as possible and giving them the desired public space, especially in education is very important. This requires annual budgeting for language development (at both state and federal levels). Furthermore, when a language is marginalised, dissonance in the society could result. Therefore, all 
Nigerians need to be carried along, given the right information in their languages, and made to feel important and responsible. This article discusses some of the developmental roles of language and makes a case for the recognition and preservation of the linguistic diversity in Nigeria for a sustainable future.

\section{Language Diversity and Sustainable Development: An Overview}

Language diversity is an undeniable reality in the world. Nigeria is one of the most linguistically diverse countries in the world. In any effort to improve human life, language plays a leading role, since it is both a thinking tool and the means through which human thoughts are given expression. The major targets of the SDGs are the vulnerable populations in the world. Although many factors can combine to make a group of people vulnerable, inability to speak the dominant language is undeniably one of such factors. Unfortunately, language matters have often been taken for granted in the developmental plans both at the national and international levels. According to Marinotti (2017), Although the rhetoric surrounding the SDGs stresses inclusiveness, multidirectional communication, and reaching the world's least advantaged citizens, policy efforts often disregard the very essence of human communication - language - easily undermining such efforts, and ultimately hindering progress toward the achievement of the SDGs (p. 2-3).

Similarly, in their review, Ugwu and Ogunremi (2019) observed that language was not given any significant attention in the plans of Nigeria for the actualization of the SDGs, even though lack of effective communication contributed to the failure in achieving the Millennium Development Goals (MDGs). To facilitate the achievement of the SDGs in Nigeria, the indigenous languages play essential roles, since the local people would be able to understand, accept and support the initiatives of the government aimed at achieving the goals (Ugwu \& Ogunremi, 2019). Moreover, initiatives that have placed a strong emphasis on articulating language as a central aspect of their development-related goals have often led to very positive results (UNESCO Bangkok, 2012).

Sustainable development also involves knowledge economy, which could be shared by communicating to the poor and vulnerable groups representing the real targets of the SDG, in a language that they understand. In this way, communication and inequality gaps are reduced between those who have the knowledge and the people who need it to improve their lives. To bridge these gaps, Marinotti (2017) recommends that members of the development community need "to understand the lives, experiences, and goals of the primary stakeholders in development" (p. 3). Language is the means to understand people's way of life and their cumulative experience and worldview, so satisfying the basic human desire for belonging (Mitchell \& 
Miller, 2019). Language is the heart of a culture, the powerful engine that pumps out people's interpretations and meanings in the form of silences and words (Essomba, 2010).

Reflecting on the importance and uniqueness of every language, Andriamiseza (2000) asserts that no linguistic discrimination can be justified. Language is a tool for critical thinking, decision making, acquisition and exchange of knowledge, planning and executing of projects aimed at improving life (Ugwu \& Ogunremi, 2019). Iwara (2008) links the inability of the respective Nigerian governments in achieving set objectives to a lack of a language for thinking. How is it that a country with up to 500 indigenous languages lacks a language to think with? The answer is not far-fetched. The indigenous languages are not recognised in the key sectors of economy, education, politics, international relations, trade and commerce, meaning that those who can function only in them are automatically cut off from full participation and in the developmental plans of the government. Hence, there is a disconnection among those who make the plans, those who execute them, what is planned, and what and how these plans are executed. Meanwhile, English, which is spoken mainly by the literates, remains the preferred language.

Neglecting of the indigenous languages spoken by the already vulnerable populations in Nigeria means leaving these behind in most of the initiatives of the government aimed at achieving sustainable development because they cannot participate in what they do not understand. Marinotti (2017) points out that vulnerable populations "are primary stakeholders in the successful achievement of the SDGs" (p. 3) but that failure to account for language and language diversity during the formulation and implementation of policy results in disproportionate effects on them. However, vulnerability, notes DeGraff (2019) is not an inherent quality of any given population, rather, the specific aspects of geo-politics and language policies themselves actively render it vulnerable. Language is also a major tool to think out solutions to the myriads of problems confronting humanity. Those who suffer injustice in any form deserve a fair hearing. Thus, appropriate avenues must be created for the vulnerable members of the society to express themselves, to voice out their experiences of injustices and to be heard.

Sen (2006) argues that the ultimate goal of all developmental effort is to enlarge human potentials and freedom, while freedom of choice is in itself both a principal means and an end for development (as cited in Romaine 2015, p. 43). In other words, freedom (including linguistic freedom), is at the heart of development. People who are under bondage cannot develop their potentials. Both the will and the power to develop self and others come from within. Therefore, ensuring freedom of expression, of participation in national life, and making conscious efforts to be what one wants to be, are all aspects 
of sustainable development. These are guaranteed if people are empowered or enabled to empower themselves through the language they speak, think and act with. An imposed language (English), in which most Nigerians are barely able to speak or function with cannot serve this end. UNESCO Bangkok (2012) states that "policy makers who understand the vital role of languages will most likely create better development planning" because focusing on languages could enhance communications and participation. On the other hand, "opportunities may be lost when the role of language is forgotten" (p. ).

\section{Language Diversity, Quality Education and In (equality)}

At least three of the SDGs are directed towards ending inequality and improving the quality of life, including quality education, zero hunger and gender parity. So far, some segments of the society are feasting while others are starving, have no access to quality healthcare, education and social amenities; there is inequality. Closing the inequality gap would mean addressing its root causes. However, access to quality education is globally recognised as the road to improving the quality of life and reducing inequality in a society. Language is undeniably the major vehicle for delivering education and lifelong learning opportunities for all, which is the $4^{\text {th }}$ goal. This goal, according to the United Nations (2017) "goes beyond school enrolment and looks at proficiency levels, the availability of trained teachers and adequate school facilities, and disparities in education outcomes" (p. 5).

Closely related to the above is the achievement of gender equality (Goal 5), including empowering all women and girls and ending gender-based discrimination in all its forms. Education is the foundation for socio-economic and socio-political empowerment. An educated woman is able to make decisions that can positively contribute to her own well-being, that of her children, and the society at large (Ugwu \& Ogunremi, 2019). Gender parity cannot be achieved without equal access to education. The United Nations (2017) report that "marriage ends or severely limits girls' education, autonomy and economic potential" and that "societal assumptions and expectations of women's roles as caregivers and mothers also curtail their income" (p. 12). Moreover, "children from ethnolinguistic minorities - and especially girlsare disproportionately represented among those who are not receiving any, or adequate, education" (UNESCO Bangkok, 2012). Such education will be more successful if delivered in the indigenous languages.

If education is important in sustainable development, so is language (Ugwu \& Ogunremi, 2019). Language used for delivering education to both children and adults is crucial to understanding and learning (Global Education Monitoring Report, 2016). Quality education, delivered in a language that learners can speak and understand guarantees retention, improves access, and enhances learning (Pinnock \& Vijayakumar, 2009; UNESCO Bangkok, 
2012). Conversely, "education received in a foreign language gravely affects the children's intellectual and psycho-social development" (DeGraff, 2019). The relationship between proficiency in the language of instruction and academic achievements has been well established by scholars (Fakeye \& Ogunsiji, 2009; Nade, 2016; Ozowuba, 2018; Agirdag \& Vanlaar, 2018; Grisso, 2018). While acquisition of English, which is the national language, is important, it should not be done at the expense of learning, which is the primary goal of schooling, and mother tongue-based multilingual education (MTBME) is the ideal. Unfortunately, even though the national policy on education stipulates MTBME, it is yet to be actualised in schools. Andriamiseza (2000) believes that any society that does not value multilingualism may undermine linguistic diversity, quality education and integration. Education in the mother tongue at the early stage has been known to give children a stronger linguistic background for further learning in secondary school. According to UNESCO "children who receive a good educational foundation at pre-primary and primary school levels are in a much better position when they go on to navigate life's challenges as adults" (Bangkok 2012). Research has shown that MTBME, which involves using the mother tongue in the first years of school and continuing for as long as possible (6 - 8 years) gives children good foundations, improves their performance, reduces failure and dropout rates, increases family support of the children and breaks the cycles of exclusion (Pinnock \& Vijayakumar, 2009; UNESCO Bangkok, 2012). Examples of countries that have successfully experimented with MTBME include Finland, Philippines, Hawaii, India and Papua New Guinea. The Ife 6-year primary project in Nigeria (Fafunwa, Macaulay, \& Sokoya, 1978) also gives credence to the importance of using the indigenous languages in education. Table 1 reports research-based evidence on how language of instruction can adversely affect children's learning, if the preferred language is not their mother tongue (Pinnock and Vijayakumar 2009). In view of the many obstacles that education in a second or foreign language constitute to learners, DeGraff (2019) sees an urgent need to decolonize the school systems globally. Such decolonisation is presently needed in all places where a foreign language remains the medium of education, and especially where such language "was purposefully chosen as a tool to annihilate the indigenous languages" and "still exerts oppressive control over the speakers of these indigenous languages" (DeGraff 2019). English language in Nigeria is undeniably a colonial garment, which presently threatens the survival of many local languages, reduces their vitality, undermines their importance and in turn, reduces the quality of life of many Nigerians - as it denies many citizens equal opportunity to education and other areas of national life. 
Delegates to the World Education Forum (2000) reaffirmed that languages and values should be the foundation for the development of African education systems. The group emphasises that everyone should have "the opportunity to receive a basic education of good quality that focuses on the "whole" person, including health, nutrition and cognitive and psycho-social development" (p. 58). In order to achieve this, education systems must be able to adapt to the individual needs of all learners and the barriers to accessibility, including issues such as language of instruction must be analysed and addressed. Through this, it is hoped that the educational system would be able to include the excluded. Unfortunately, language of instruction remains a major barrier to effective schooling in Nigeria. For indigenous or heritage language minorities, especially speakers of low-prestige languages, inequality is reinforced through the institutionalisation of legal, economic, educational, and social discrimination in the form of languages of education and government that are inaccessible or difficult to access (Marinotti, 2017). However, "comprehensive language policy and plan based on a progressive language clause offer broad opportunities to promote peace and give concrete effects to the values of human rights, equality, tolerance and a better life for all" (Beukes, 2010).

Goal 8 focuses on the promotion of sustained, inclusive and sustainable economic growth, full and productive employment and decent work for all. Access to quality education is needed for this to be achieved. Illiteracy closes opportunities but literacy opens the door to wellness, creativity, information and growth. Economic growth, which is sustainable and inclusive, would make more people able to "escape poverty as opportunities for full and productive employment expand" (United Nations, 2017, p. 7). Moreover, education (both formal and informal) would better enable the citizens to "build resilient infrastructure, promote inclusive and sustainable industrialization and foster innovation" (Goal 9). Language can be an aid or a barrier to thinking and innovation. The more proficient a person is in a given language, the more she/he can use it to think.

The $10^{\text {th }}$ sustainable development goal aims at reducing inequality in the world, ensuring that migrants are safe and "strengthening the voices of developing countries in international economic and financial decisionmaking" (United Nations, 2017, p. 8). How can the voice of the local population be heard, if their languages are silenced? The use of dominant languages in the world economic forum closes the door to the full participation of many indigenous people who are not only denied access to the information from such forum but are poorly represented because of the lack of understanding of their plights. Nigerian languages need to be projected to the outside world; but a lot of homework needs to be carried out first. Charity, they say, begins at home. These languages must be recognised, valued and 
given public space in Nigeria before they can be confidently projected to the outside world. On the contrary, if they are undervalued at home, the outside world will not accept them.

\section{Language Diversity, Biodiversity and Quality of Life}

In order to achieve the SDGs, every plan of action should be peoplecentred. Nigerian farmers, most of whom are not literate, and therefore, can only function in the indigenous languages need information and training on modern agricultural innovations and best practices that could boost farm yields, control pests, and improve their lots. They also need information on how to preserve food and reduce waste. Delivering this information to them in the indigenous languages rather than in English will be more advantageous. Moreover, their access to the global markets is more guaranteed, if the language they speak is promoted and used in trade and commerce. If the opposite occurs, they risk being cheated or losing their money to middlemen. The needed effort to "build resilience and limit climate-related hazards and natural disasters" (United Nations, 2017, p. 9) must include educating the local population on the need to avoid harmful practices that may increase the hazards. Climate changes are the result of human activities everywhere, their adverse effects are felt by all, and the collaboration of all is necessary to reverse the trend. The local population needs education and enlightenment that would enable them to understand the relationship between their daily lifestyle and climate changes and how what they do could affect them as individuals, as a community and as a larger society. For example, most farmers in Nigeria rely on insecticides, pesticides and herbicides to boost agricultural production. Lack of information as well as illiteracy could make them overuse these chemicals in ways that could endanger human life, poison the land, reduce biodiversity and the terrestrial body as these harmful chemicals are washed into the rivers and seas. The indigenous languages are vital for educating the public and creating awareness on the effects of some of these practices. If the environment is secure and the trend of climate changes is reversed, the local populations have better chances of living healthier lives. Healthy ecosystems produce multiple benefits for all communities: clean air, water, food, raw materials and medicines, to name a few (United Nations, 2017, p. 48).

Many Nigerians, especially those in the rural villages rely on alternative medicine for treating common diseases and infirmities. They know the names of medicinal plants in their native languages as well as how to use them. Loss of biodiversity, especially of such plants could make life and survival more difficult for them, especially as many communities do not have well-equipped hospitals and even where these exist, poverty reduces their chances of accessing them. They need to be educated on how the loss of biodiversity could adversely affect their own survival. The indigenous 
languages are the best medium for delivering such information or enlightenment programmes.

\section{Language Diversity, Social Cohesion and Quality of Life}

The objective of Goal 11 is to "make cities and human settlements inclusive, safe, resilient and sustainable". Also, Goal 16 focuses on the need to promote peace and justice. Peace is both the pre-condition and goal of any society seeking to live life fully with a deep and abiding respect for human rights (Essomba, 2010). Peace is urgently needed in Nigeria, and languages are vital instruments for establishing and maintaining the culture of peace. Peace begins with dialogue and language is the primary tool for successful dialogue. "Since wars begin in the minds of men, it is in the minds of men that the defences of peace must be constructed" (UNESCO, 1945). Upholding language diversity is a necessity for resilience and peaceful co-existence. "Respect for the languages of persons belonging to different linguistic communities therefore is essential to peaceful cohabitation" (UNESCO $2003 \mathrm{~b}$, p. 16). Increasingly, research finds both correlation and causation relationships between language grievances and threats to social cohesion (Bianco, 2016). Peace can be guaranteed by education to the extent that it promotes linguistic and cultural diversity as positive values, and develops approaches and practices that favour these forms of diversity within education systems (Andriamiseza, 2000). Policies that favour one language over the others have been known to cause ethnic conflicts and political instability in countries such as Pakistan, Thailand, Macedonia, Turkey, Sri Lanka, China and South Africa (de Varennes, 2010; Pinnock \& Vijayakumar, 2009, p. 8). The delegates to the World Education Forum (2000), envisioned "the resurgence of a vibrant Africa, rich in its cultural diversity, history, languages and arts, standing united to end its marginalization in world progress and development" (p. 27 ). The indigenous languages remain the best medium for transmitting the Nigerian culture and tradition to the younger generations.

The local populations rely on credible information that promotes good health and well-being. Improving reproductive, maternal and child health, eradication of different forms of diseases and health hazards (Goal 3), would be best achieved where there is mutual communication and trust between the health workers and the local population. Ignorance and illiteracy encourage people to engage in practices that could plunge them further into disadvantaged positions. In 2018, up to 167 health workers were killed and 710 were injured in different parts of the world, including Nigeria (International Council of Nurses, 2019). Such attacks were linked to a lack of trust as well as heightened insecurity and tension, leading local people to refuse medical assistance simply due to language misunderstandings. A possible solution could be training health workers from and in the rural 
villages who are able to share and communicate through indigenous languages. As a result, local people receive health information and services from people they can understand and trust.

\section{Suggestions and Conclusion}

If vulnerability is caused through a process that brings exclusion and marginalisation, then empowerment must also start with letting people speak for themselves and listening to them in their own words. This is hindered in Nigeria as the local people are silenced because they cannot function in the official language. Proficiency in English determines access to basically all the essential services of the government, to wellness and to opportunities, including education. Unfortunately, this is to the detriment of the vulnerable and poor, who are often left behind. With the present mere-collapse of the public educational system, for example, the majority of the poor are not able to send their children to private schools with better learning opportunities. Even for many students in the so-called standard private schools, English still poses a problem to knowledge acquisition.

Meanwhile, English has been used to dehumanise Nigerians through colonialism. It has been the language of the oppressors (the white colonialists); now, it is the language of the neo-colonialists: a tool for fanning the flame of inequality and lacking of inclusion. Favouring English language above the indigenous languages, most especially in education, is nothing but linguistic imperialism. The Nigerian languages must be used to decolonise our educational system and re-humanise the citizens. Furthermore, since it was through the school system that the status of the indigenous languages has been diminished and consequently undervalued, education must be the primary tool for resuscitating these languages and reawakening the consciousness of citizens to cherish them.

Moreover, since teachers have been used to shift the attention of children from their mother tongues to English, they must also be the agents for reversing such trend. Achieving this is not going to be easy. It calls for a "linguistic battle" between the oppressed and the oppressors, the power and the pen. However, this call does not translate into denying the citizens access to English language, which remains the national language, a lingua franca and the world language. What is needed, rather, is a mother tongue-based multilingual system of education where the indigenous languages and English can be jointly recognised and used to deliver quality education. Thus, the road to achieving sustainable development would be opened to all Nigerians. 
Table 1: How language of instruction can adversely affect children's learning

1. Children in rural locations are much more likely to drop out of school unless they can learn in their first language

2. In all settings, children perform worse across the curriculum when their first language is not used to teach

3. Children do badly in an national or international language which is used for teaching if they do not use it at home

4. Children never become fully literate if they do not already know the language of literacy well

5. Children may never make it into secondary education if they struggle with language in primary school, even though by their teens their ability to learn advanced second language might be greater

6. Groups who do not have easy access to dominant languages will continue to see their interests as not being served by the state

7. If school assessments are conducted in a language that a child does not understand well, it will be impossible to get a picture of their real capacities and to judge school quality.

\section{References:}

1. Andriamiseza, N. (2010). Multilíngualísm and peace. In The Management of Linguistic

2. Diversity and Peace Processes. Centre UNESCO de CatalunyaUnescocat (p. 255-256). Retrieved from https://www.academia.edu/21116697/The_Management_of Linguistic_Diversity_and_Peace_Processes

3. Beukes, A. M. (2010). Africa: Language diversity and the culture of peace in South Africa.

4. In The Management of Linguistic Diversity and Peace Processes (p. 273-282). Centre

5. UNESCO de Catalunya-Unescocat. Retrieved from https://www.academia.edu /21116697/The_Management_of Linguistic_Diversity_and_Peace_Processes

6. Bianco, J. L. (2016). Conflict, Language Rights, and Education: Building Peace by Solving Language Problems in Southeast Asia. Language Policy Research Network Brief. Retrieved from http://www.cal.org/lpren/pdfs/briefs/conflict-language-rights-andeducation.pdf

7. de Varennes, F. (2010). The management of diversity in the context of peace processes. In The Management of Linguistic Diversity and Peace Processes (p. 263-269). Centre UNESCO de CatalunyaUnescocat. Retrieved from https://www.academia.edu 
/21116697/The_Management_of_Linguistic_Diversity_and_Peace_P rocesses

8. Essomba, M. A. (2010). Foreword. In The Management of Linguistic Diversity and Peace Processes (p. 247-248). Retrieved from https://www.academia.edu/21116697_/The_Management _of_Linguistic_Diversity_and_Peace_Processes

9. Fafunwa, A. B., Macaulay, J. I., and Sokoya, J. A. F. (eds.) (1989). Education in Mother Tongue: The Ife Primary Education Research Project. Ibadan: University Press Ltd.

10. Fakeye, O., and Ogunsiji, Y. (2009). English language proficiency as a predictor of academic achievement among EFL students in Nigeria. Euro Journals of Scientific Research, 37(3) 490-495. Retrieved from http://www.eurojournals.com/ejsr.htm

11. DeGraff, M. (2019). Against Apartheid in Education and in Linguistics: The Case of Haitian Creole in Neo-Colonial Haiti. In: Decolonizing Foreign Language Education. Retrieved from https://www.researchgate.net/publication/335505887_Against_Apart heid_in_Education_and_in_Linguistics_The_Case_of_Haitian_Creol e_in_Neo-Colonial_Haiti

12. Global Education Monitoring Report. (2016). Policy paper 24. If you don't understand, how can you learn? Retrieved from http://unesdoc.unesco.org/images/0024/002437/243713E.pdf

13. Grisso, L. C. (2018). The Relationship Between English Language Proficiency And Academic Achievement in English Language Learners. Unpublished Doctoral Dissertation, Liberty University. Retrieved from https://plu.mx/plum/a/?repo _url=https://digitalcommons.liberty.edu/doctoral/1832\&theme=plumbigben-theme

14. Iwara, A. U. (2008). The Linguistic Situation in Nigeria and its Implication for Sustainable Development. An Inaugural Lecture. Ibadan. Ibadan University Press.

15. Marinotti, J. P. ed. (2017). Symposium on Language, the Sustainable Development Goals and Vulnerable Populations. Final Report. Study Group on Language and the United Nations. Retrieved from https://www.languageandtheun.org/symposium2017report.html

16. Mitchell, D. and Miller, M. (2019).Reconciliation through language learning? A case study of the Turas Irish language project in East Belfast, Ethnic and Racial Studies, 42:2, 235-253, DOI: 10.1080/01419870.2017.1414278

17. Nade, P. B. (2016). Mastery of language of instruction and its influence on student academic performance: evidence from secondary schools in

Tanzania.

Retrieved

from 
https://internationaljournalofresearch.com/2016/12/03/mastery-oflanguage-of-instruction-and-its-influence-on-student-academicperformance-evidence-from-secondary-schools-in-tanzania//

18. Ozowuba, G. U. (2018). Relationship Between English Proficiency and Academic Achievement of Nigerian Secondary School Students. Walden University ScholarWorks. Retrieved from https://scholarworks.waldenu.edu/dissertations

19. Pinnock, H. and Vijayakumar, G. (2009). Language and education: the missing link from http://www.unesco.org/education/EFAWG2009/LanguageEducation. pdf

20. Romaine, S. (2015). The Global Extinction of Languages and Its Consequences for Cultural Diversity. Retrieved from http://www.springer.com/cda/content/document/ cda_downloaddocument/9783319104546-c2.pdf?SGWID=0-0-451492462-p176900229

21. United Nations (2017). The Sustainable Development Goals Report. Retrieved from https://www.un.org/sustainabledevelopment/sustainabledevelopment-goals/

22. Ugwu E. O. and Ogunremi, P. O. (2019). Nigeria and the sustainable development goals: Why the indigenous languages count. European Scientific Journal, 15(5), 52-68.. Doi:10.19044/esj.2019.v15n5p52

23. UNESCO (2003a). Language Vitality and endangerment. Retrieved from

http://www.unesco.org/new/fileadmin/MULTIMEDIA/HQ/CLT/pdf/ Language_vitality_and_endangerment_EN.pdf

24. UNESCO, (2003b). Education in a multilingual world. UNESCO Education Position Paper. Retrieved from http://unesdoc.unesco.org/images/0012/001297/129728e.pdff

25. UNESCO (1945). UNESCO Constitution. Retrieved from http://portal.unesco.org len/ev.php URL_ID=15244\&URL_DO=DO_TOPIC\&URL_SECTION=201.ht $\mathrm{ml}$

26. UNESCO Bangkok (2012). Why language matters for the Millennium Development Goals. Retrieved from http://unesdoc.unesco.org/images/0021/002152/215296e.pdf

27. World Education Forum (2000). Dakar Framework for Action, Education for All: Meeting our Collective Commitments. Retrieved from http://portal.unesco.org/en/ev.php-

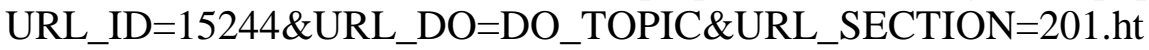
$\mathrm{ml}$ 